\title{
The Secured Proficient Smart Electronic Voting System
}

\author{
C.K. Gomathy, V. Geetha, Venkata Nagendra, Venkata Sai Ram
}

\begin{abstract}
In this contemporary democratic system, the election commission of India is facing difficulty in finding fake votes. Right now framework, the political decision commission of India is confronting trouble in discovering counterfeit votes. To beat this, we presented a novel crossover Electronic democratic machine utilizing a face acknowledgment framework. Right now and numerical models, for arranging face including Convolutional Neural Network. In this mechanized framework, in this paper recommended and advise an EVM machine which confirms the facial picture of a voter through a CNN based face recognizer to checks it with the pre-caught pictures gave in the database. The databases checked based on the outcome being sure, it is accept the voter is a valid one. This move towards to make the choice for an ideological group, if the outcome is negative, the voter can't make their choice. After this procedure, the pictures are put away in another database to check the democratic rate. After this process, the casted images are stored in another database to check the voting percentage.
\end{abstract}

Keywords : Smart Democratic Framework, Deep Learning, EVM Face Recognition, EVM, Smart Voting System.

\section{INTRODUCTION}

India is the biggest Democratic country on the planet. It involves around 1000 million voters who make their choice in the races. The Indian political decision commission is a self-governing body of the Constitution, which has effectively hold races to the Parliament and numerous other administrative congregations of the state for a couple of years in a succinct, supported, confirmed and serene way. The Commission is prevalently known as a Global Gold Standard in Election Management over the World. The Commission is notable as it has effectively grasped, embraced and later executed the best in class innovative advances in accomplishing a worldwide summit according to the procedure of political race has been concerned. The Electronic Voting Machine (EVM) fills in as the important appliance to verification the section of votes, its handling lastly tallying the votes with no manual error in a protected and believable manner. Face location and acknowledgment

Revised Manuscript Received on April 25, 2020.

* Correspondence Author

Dr.C.K. Gomathy*, Assistant Professor in CSE Department, SCSVMV Deemed to be University

Dr.V. Geetha, Assistant Professor in CSE Department, SCSVMV Deemed to be University

Mr. Venkata Nagendra, UG Scholar CSE Department, SCSVMV Deemed to be University

Mr. Venkata Sai Ram, UG Scholar CSE Department, SCSVMV Deemed to be University

(C) The Authors. Published by Blue Eyes Intelligence Engineering and Sciences Publication (BEIESP). This is an open access article under the CC BY-NC-ND license (http://creativecommons.org/licenses/by-nc-nd/4.0/) has been a noteworthy cooperation apparatus utilized in the security frameworks, get to control which has increased enough ubiquity over the most recent couple of decades. With the innovative progression, there has been a monstrous blast of man-made consciousness. In this manner numerous PC vision security methods, for example, face acknowledgment framework, signal recognition, retina location have increased some significance as the framework is non-nosy in nature and it has end up being very helpful to decide one's character extraordinarily.

The regularly a face acknowledgment component contains the accompanying: identifying the face, its arrangement discovery, separating out the highlights, discovering the similitude and its estimation. In contrast with the traditional AI strategies, the enormous scope profound learning approaches have fundamentally given much better and adaptable exhibitions considering picture handling and exactness. Learning progressive portrayals with a solitary or a couple of calculations is trying in nature and has essentially beaten records in picture acknowledgment strategies, normal language handling, semantic division and a few different assignments. The surrounded by all these, CNN gives the most encouraging outcomes in picture acknowledgment and arrangement errands as they misuse the nearby setting data utilizing channels of various sizes. CNN is a kind of neural system that is prevalently used to extricate highlights from the information by utilizing different convolution strategies. LeCun at first proposed the focal thought of CNNand applied in the assignment of penmanship acknowledgment. The possibility of ImageNet formulated by Krizhevsky, Sutskever and Hinton has denoted an unrest in PC vision. It is viewed as a compelling production in PC vision and indicated that CNNs beat acknowledgment exhibitions on the off chance that we contrast with handmade based strategies. A Right now has proposed a face acknowledgment dependent on the highlights separated by a convolutional neural system from the caught picture of a voter. On the off chance that the caught picture's highlights coordinate with those current pictures put away in the database, the outcome is considered as positive and the voter is approached to make choice for an ideological group. When the vote has been casted, all the facial arrangement subtleties relating to the voter gets erased from the framework, so that if a similar voter seeks casting a ballot, the framework identifies the vindictiveness and forestalls it in a split second. Right now, above-expressed security issue during races in India has been managed face acknowledgment based electronic democratic framework.

\section{LITERATURE REVIEW}


Face Detection is a generally new idea. In 2001, Viola and Jones previously proposed a course Adaboost structure and made the face identification constant. Off late, the Convolutional Neural Network has been utilized in PC vision and example acknowledgment to accomplish the equivalent. Numerous CNN-based item discovery strategies which are proposed have improved the district proposition based CNN strategy and proposed the Faster R-CNN outline work, this system presented the grapples technique and made area proposition a CNN order issue, which could be prepared in the entire net during the preparation organize.Most face acknowledgment techniques utilized adjusted faces as the information, it had been demonstrated that receiving arrangement in the test stage could have $1 \%$ acknowledgment exactness enhancement for the LFW dataset. The standard path for face arrangement was anticipating facial tourist spots from the recognized facial patches, for example, eyes, nose and mouth. What's more, the geometric change between the places of the anticipated facial tourist spots and the pre-characterized milestones was applied to the facial patches. The adjusted appearances to known face characters were then taken care of into the profound systems and were arranged by the last characterization layer for preparing the discriminative element extractors, the moderate bottleneck layer was taken as the portrayal. A colossal assortment of face identification, check and acknowledgment is available. The commitment of all utilization a mind boggling arrangement of different stages, which utilize and consolidate the yield of a profound convolutional coordinate with PCA for dimensionality decrease and a SVM for grouping.

\section{METHODOLOGY}

The Facial recognition is biometric understandings that approximate remarkable qualities around ones face. Face acknowledgment distinguishes individuals from the attributes of photographs and recordings. So a face be familiar with distinguish the facial highlights and contrast the qualities and those present inside the knowledgebase. An element comparability metric guide in computational closeness coordinating and from this time forward the most predominant mark is appended as the name of the picture. The framework will neglect to perceive the individual. This is the means by which face acknowledgment continues and if two people are same, their element comparability is excessively high.

This paper utilizes a profound CNN model with the end goal of highlight extraction from the pictures. LFW dataset test has been considered, at that point at long last the dataset has been altered with the pictures of the legitimate voters assessed our examination. The accompanying areas will exhibit the two-level security confirmation gave by the proposed framework. To start with, the whole module of face acknowledgment has been clarified, for example, an) outline of the profound CNN design, b) discovery and change on input pictures which guarantees that the countenances are effectively adjusted former taking care of them into the CNN. C) Utilize the CNN to extract the dimensional portrayals, or embeddings, of appearances from the adjusted info pictures as Euclidean separation straightforwardly identifies with a proportion of face similitude d) at last figure the embeddings to formalize the closeness. The proposed work process of the whole structure has been appeared in the fig. 1

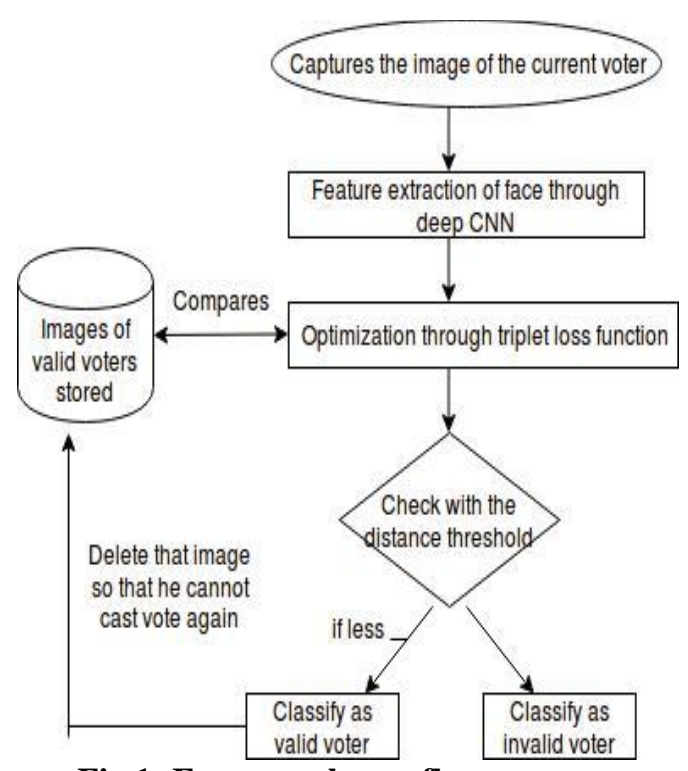

Fig 1: Framework overflows process

\section{SYSTEM ARCHITECTURE}

The possibility of our model is for the most part gotten from the Inception Architecture of Google. The engineering can be portrayed as : a multi-layer feed-forward layer comprising of 200 middle of the road hubs with another L2 weighted regularization layer with convolutional layer in the middle. while the replica is attainment ready with a triplet misfortune work, an implanting $\mathrm{f}(\mathrm{x})$ of picture $\mathrm{x}$ to such an extent that the relative separation estimated between various sets of tests get augmented while that between comparative sets of tests gets limited. The reason for the misfortune work is to bring close the grapple record or the present picture xai and a constructive picture xpi and the adverse record xni (some other individual) will be isolated by some impressive enormous separation and the edge will be $\alpha$. The outcomes and investigation has been appeared in the accompanying area. The face-detection, modify and control has been done on the pictures.

The dimensional establish the vectors are then determined by taking care of the adjusted and scaled pictures into the pre-prepared system. While figuring the separation between the pictures of same individual, the separation must be generally not as much as that between two distinct people. That is the primary utility of utilizing a triplet misfortune work.

A similar calculation has been finished utilizing the tradition dataset of the pre-caught photos from the electorate who are joyful to make their choice in the political decision. In this manner, the test picture for example the individual as of now ready to make his choice is then contrasted and the database pictures, on the off chance that the examination score is beneath the ideal edge, at that point the voter is considered as legitimate and is permitted to experience through the following verification level for example the unique mark acknowledgment framework

\section{WORKING MODEL AND RESULTS}

Published By:

Blue Eyes Intelligence Engineering

\& Sciences Publication 2238 (C) Copyright: All rights reserved.

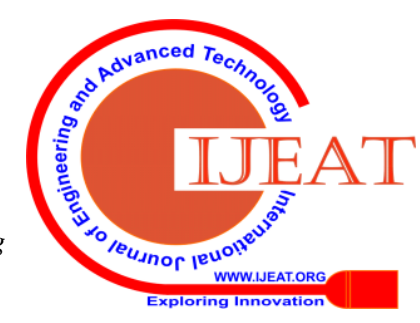


In the proposed framework, we have tested the system through one degree of confirmation biometric framework. A face recognizer decides the qualities of an individual's picture by catching the equivalent through a camcorder. The whole arrangement has been ruined down including the surrounding area of the eyes, nose, jaws and mouth. Their relative departure fills in as the one of a kind element to distinguish an individual. Those estimations are reserved surrounded by a file and used to think about a client's character when he remains before the camera. In not so distant future, we might want to fuse unique finger impression acknowledgment framework as second degree of confirmation framework to destroy any type of safety measures dangers to universal races in India.

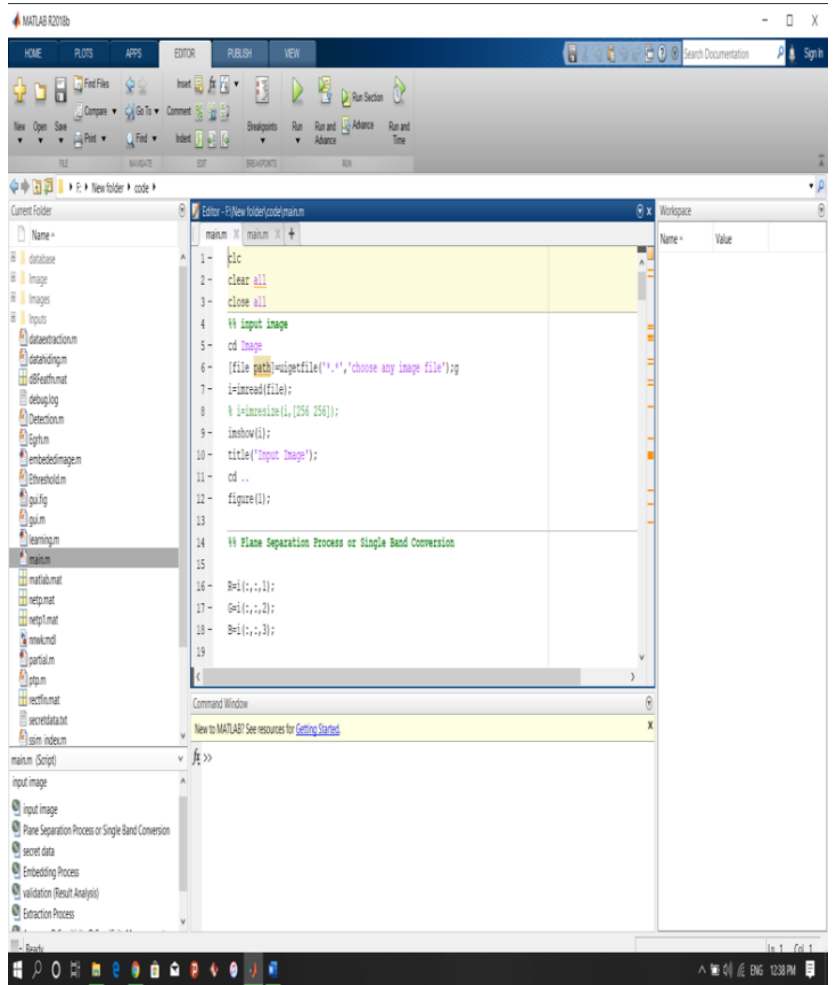

Fig 2:Finger print simulations code form

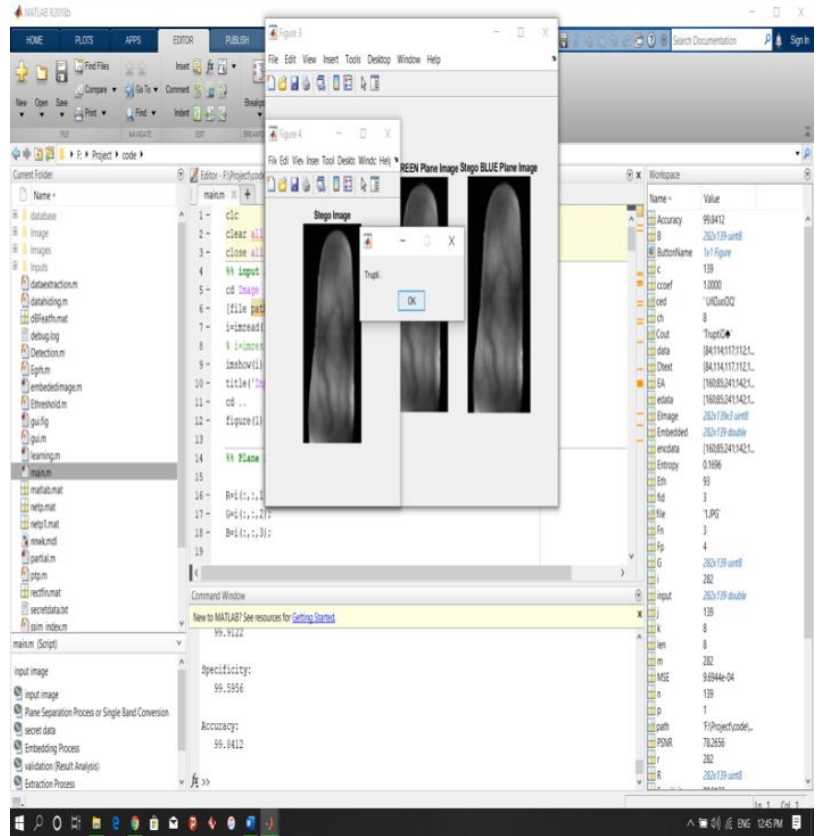

Fig 3: Finger print Authentication System
The face acknowledgment based electronic voting system has been checked on a common dataset and a custom dataset arranged for the function of testing real-time.

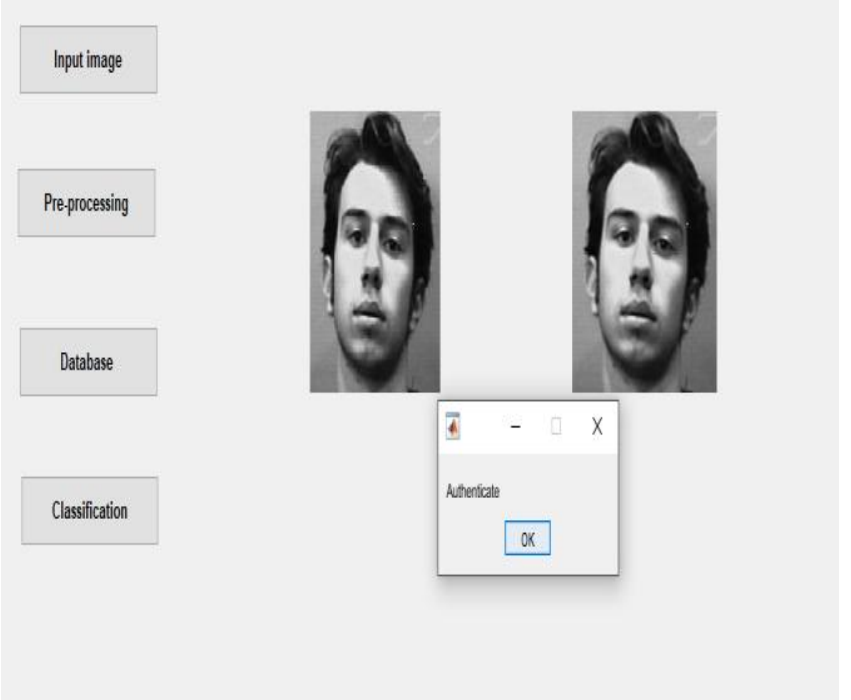

Fig 4: Face Recognition Authentication System

\section{CONCLUSION}

Face acknowledgment includes countless difficulties with regards to manage the visual examination. Perceiving face of people is a serious testing task as those can display a colossal variety of attributes old enough, demeanour, nose, separation between two eyes and so on. Along these lines, this advancement or approach assumes a critical job in security applications, for example, authoritative archives ID, distinguishing proof of fear based oppressors in the open spots like railroad station, ports, shopping centers. In spite of the way that an enormous number of systems have demonstrated to work superiorly as far as identification and acknowledgment of human faces, still it stays testing to build up a computationally productive calculation to coordinate the human face with those present in the huge database. In this manner face acknowledgment can be alluded to as a predominant PC vision task. Right now, secure and bother free face acknowledgment based electronic democratic machine has been proposed which is planned to illuminate the tamparability and security issues looked during the races in India. The proposed strategy has been utilized continuously, runs consummately on the standard benchmark dataset just as the custom dataset arranged by us. The presentation has been exceptional contrasted with the conventional methodologies on account of the more profound design of the convolutional neural systems. Over the most recent two decades, countless government-claimed organizations have directed the races in India by permitting the electorate to make their choice through automated arrangement of Electronic democratic machine. The EVM gadgets are very straightforward in plan, simple to utilize, and dependable also. Yet, during nowadays, there have been reports of its unpredictable use. In any case, from the purpose of business and consumer loyalty, these advanced gadgets have increased a lot of fame and our technique vows to fill in as an independent validation framework.

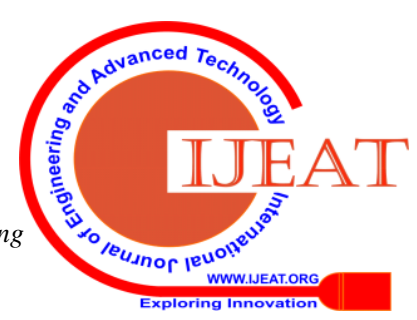




\section{REFERENCES}

1. C.K.Gomathy,"Cloud Computing: Business Management for Effective Service Oriented Architecture" International Journal of Power Control Signal and Computation (IJPCSC), Volume 1, Issue IV, Oct - Dec 2010, P.No:22-27, ISSN: 0976-268X .

2. Dr.C K Gomathy, Article: An Effective Innovation Technology In Enhancing Teaching and Learning Of Knowledge Using Ict Methods, International Journal Of ContemporaryResearch In Computer Science And Technology (Ijcrcst) E-Issn: 2395-5325 Volume3, Issue 4,P.No-10-13, April '2017.

3. M. Liang and X. Hu, Recurrent convolutional neural system for object acknowledgment, 2015 IEEE Conference on Computer Vision and Pattern Recognition (CVPR). pp. 33673375, 2015.

4. Dr.C K Gomathy, Article: A Web Based Platform Comparison by an ExploratoryExperiment Searching For Emergent Platform Properties, IAETSD Journal For Advanced Research In Applied Sciences, Volume 5, Issue 3, P.No-213-220, ISSN NO: 2394-8442,Mar/2018

5. Dr.C K Gomathy, Article: A Study on the recent Advancements in Online Surveying ,International Journal of Emerging technologies and Innovative Research ( JETIR ) Volume5 | Issue 11 | ISSN : 2349-5162, P.No:327-331, Nov-2018

6. SumanthImmanuvel, Dr.C.K.Gomathy,Article:A machine Learning Approach to markAttendance using Haarcascade Classifier, International journal for research andDevelopment in Technology,Volume-11,Issue-3,March 2019.(ISSN No:2349-3585)

7. M. A. K. Mohamed, A. El-Sayed Yarub, and A. Estaitia, Automated Edge Detection Using Convolutional Neural Network, Int. J. Adv. Comput. Sci. Appl., vol. 4, no. 10, pp. 1117, 2013

8. Dr.C K Gomathy, Article: A Scheme of ADHOC Communication using Mobile DeviceNetworks, International Journal of Emerging technologies and Innovative Research ( JETIR) Volume 5 | Issue 11 ISSN : 2349-5162, P.No:320-326, Nov-2018

9. Dr.C K Gomathy, Article: A Semantic Quality of Web Service Information RetrievalTechniques Using Bin Rank, International Journal of Scientific Research in ComputerScience Engineering and Information Technology ( IJSRCSEIT ) Volume 3 | Issue 1,ISSN: 2456-3307, P.No:1563-1578, February-2018

\section{AUTHORS PROFILE}

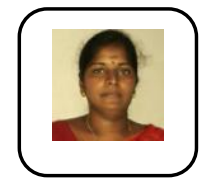

Dr.C.K.Gomathy is assistant professor in computer science and engineering at Sri Chandrasekharendra Saraswathi Viswa Mahavidyalaya ,Enathur,Kanchipuram,India. Her area of intrest lies in Software Engineering,Web Services, Knowledge Management Domain.

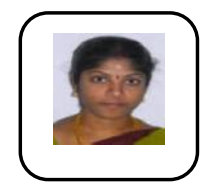

Dr.V.Geetha is assistant professor in computer science and engineering at Sri Chandrasekharendra Saraswathi Viswa Mahavidyalaya ,Enathur,Kanchipuram,India. Her area of intrest lies in Computer System Architecture Domain

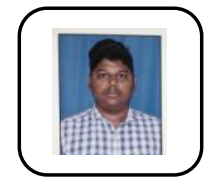

Mr. Venkata Nagendra is a UG Scholar in computer science and engineering at Sri Chandrasekharendra Saraswathi Viswa Mahavidyalaya ,Enathur,Kanchipuram,India. His area of intrest lies in Networks and Security

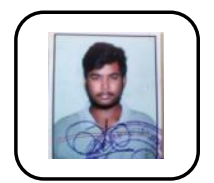

Mr. Venkata Sai Ram is a UG Scholar in computer science and engineering at Sri Chandrasekharendra Saraswathi Viswa Mahavidyalaya ,Enathur,Kanchipuram,India. His area of interst lies in Data Mining

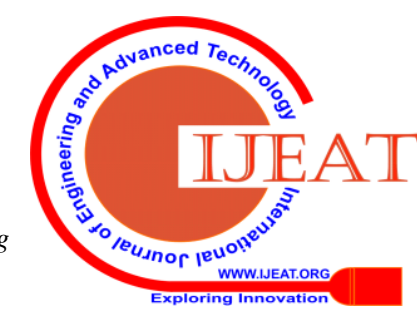

